\title{
Prevalence of Low Levels of Vitamin D in Type 2 Diabetes at the City of Mangueirinha, Paraná, Southern Brazil
}

\author{
Paulo Sérgio Chiamolera ${ }^{1}$, Cristiano Alvariza Amaral' ${ }^{1}$, Monica Cristina de Oliveira Russo' ${ }^{1}$, \\ Gilberto de Oliveira Netto ${ }^{1}$, Ricardo Augusto Fernandes ${ }^{1}$, Ricardo Teles de Andrade ${ }^{1}$, \\ José Luiz Gonçalves Buscariolli ${ }^{1}$, Denise Rosso Tenório Wanderley Rocha ${ }^{1}$, \\ Alberto Krayyem Arbex ${ }^{1,2}$ \\ ${ }^{1}$ Division of Endocrinology, IPEMED Medical School, São Paulo, Brazil
${ }^{2}$ Visiting Scholar, Harvard T. H. Chan School of Public Health, Harvard University, Boston, USA
Email: paulochiamolera@yahoo.com
}

Received 13 December 2015; accepted 11 January 2016; published 14 January 2016

Copyright (C) 2016 by authors and Scientific Research Publishing Inc.

This work is licensed under the Creative Commons Attribution International License (CC BY). http://creativecommons.org/licenses/by/4.0/

\section{(c) (i) Open Access}

\section{Abstract}

Background: Diabetes mellitus is a worldwide epidemic. In 2002 there were 173 million diabetic adults worldwide, and these numbers are expected to reach up to 300 million people by 2030 . Meanwhile, vitamin D deficiency has its worldwide prevalence directly influenced by factors as solar radiation, skin color, latitude and seasons, cultural habits of populations such as clothing and food, and these factors are important to explain the different prevalences of vitamin $D$ deficiency in the world. Methods: A prospective cross-sectional cohort study was conducted with patients in the outpatient clinic of the Health Unit of the city of Mangueirinha, Paraná, Southern Brazil. Fifty-four type 2 diabetic patients were evaluated (38 women and 16 men), aged $55.8 \pm 12.6$ years. The following variables were evaluated: age, ethnicity, presence of type 2 diabetes (DM2), hypertension, dyslipidemia, weight, BMI, WC, blood pressure, blood glucose, glycated hemoglobin, ionized calcium, PTH, 25-OH Vit, total cholesterol, HDL, LDL, urea, creatinine, uric acid and red cell/hematocrit. Results: mean BMI was $30.2 \pm 4.4 \mathrm{~kg} / \mathrm{m}^{2}$, indicating class 1 obesity in this population. Fasting glucose levels were approximately $169.8 \pm 74.5 \mathrm{mg} / \mathrm{dL}$. The $25-\mathrm{OH}$ vitamin $\mathrm{D}$ values for this population were $23.4 \pm 8.3 \mathrm{ng} / \mathrm{mL}$, and $13 \%$ of them showed $25-0 \mathrm{H}$ vitamin $\mathrm{D}$ levels above $30 \mathrm{mg} / \mathrm{dL}$. Fifty percent of those patients had vitamin D levels lower than $30 \mathrm{mg} / \mathrm{dL}$, and $37 \% \mathrm{had}$ less than $20 \mathrm{mg} / \mathrm{dL}$. Conclusions: this study suggests that vitamin $D$ is associated with low levels of vitamin $D$ in type 2 diabetic patients. Supplementation of vitamin D should be considered in diabetic patients, when levels under $30 \mathrm{mg} / \mathrm{mL}$ are found.

How to cite this paper: Chiamolera, P.S., Amaral, C.A., Russo, M.C. de O., Netto, G. de O., Fernandes, R.A., de Andrade, R.T., Buscariolli, J.L.G., Rocha, D.R.T.W. and Arbex, A.K. (2016) Prevalence of Low Levels of Vitamin D in Type 2 Diabetes at the City of Mangueirinha, Paraná, Southern Brazil. Open Journal of Endocrine and Metabolic Diseases, 6, 8-12. 


\section{Keywords}

\section{OH Vitamin D, Type 2 Diabetes Mellitus, Cardiovascular Risk}

\section{Introduction}

Diabetes is a disease that occurs due to the lack of insulin and/or inability of it to properly exert its effects, and is characterized by chronic hyperglycemia with carbohydrate metabolism disorders, lipids and proteins [1]. Its complications compromise the productivity, quality of life and survival of individuals, beyond their treatment involve high costs [2].

It is estimated that poor eating habits and lifestyle are associated with several health hazards, involving, obesity, diabetes and high blood pressure [3].

Diabetes mellitus is now considered a worldwide epidemic and it is estimated that in 1985 there were 30 million adults in the world with this disease. In 1995 this number grew to 135 million and in 2002 it reached 173 million people, and by 2030 it is expected to reach 300 millions [1].

In Brazil, the prevalence of diabetes in the urban Brazilian population, adult (30 - 69 years) is 7.6\%, comparable to that of several other countries, including those more developed. As in most other countries, type 2 diabetes, which is the most common hyperglycemia state, constitutes about $90 \%$ of diabetics [4].

Vitamin D is essential for bone homeostasis and their main source is the skin, which may be ingested with the diet; however, the majority of humans depend on the sunlight to acquire sufficient quantities of vitamin $\mathrm{D}$ [5].

There are two main forms of vitamin D: ergocalciferol (vitamin D2) and cholecalciferol (vitamin D3). The main sources of synthesis of vitamin D2 are plants (especially fungi and yeasts) and vitamin D3 is synthesized in human skin by UV-B radiation action besides being founds in certain foods [6] [7].

Vitamin D2 and D3 do not have biological functions in the body, but once ingested are transported to the liver where they are transformed into active substances [8]. These active substances, when missing, appear to be directly linked to the onset of DM2.

Vitamin D deficiency may cause rickets and osteomalacia, exacerbate bone loss in osteoporosis, but it also may be associated with multiple comorbidities, such as cardiovascular disease, hypertension, type 1 and 2 of diabetes mellitus, prostate and colon cancer [3] [9].

On the other hand, normal concentrations of vitamin D are associated with a lower incidence of cancers, such as prostate, colon and breast cancer, as well as with less diabetes [10].

The present study assessed the possible association of vitamin D with T2DM. It is known that a deficiency of this vitamin may interfere with the operation of the beta cell $(\beta)$ hindering the pancreatic secretion of insulin [11].

\section{Literature Review}

\subsection{The Importance of Vitamin D}

\subsubsection{Pathophysiology}

There are two main forms of vitamin D: ergocalciferol (vitamin D2) and cholecalciferol (vitamin D3). Vitamin D2 is synthesized by plants (especially fungi and yeasts), whilst vitamin D3 is synthesized in human skin by the action of UV-V radiation from 7-dehydrocholesterol, and is also found in certain foods, such as fish oil and egg yolk [6] [7].

Vitamin D2 and vitamin D3 have no known biological functions in the body [8]. Once ingested or synthesized in the skin, vitamin D is transported to the liver where it undergoes a first hydroxylation at carbon 25, converting it to 25-hydroxyvitamin D (25OHVitD).

The 25OHVitD is the main form of vitamin D circulating, with a half-life of around two to three weeks. Reflecting safe way the body stores this vitamin, and in the kidneys, the 25OHVitD suffers new hydroxylation with the production of its active form, 1,25dihydroxyvitamin D (1,25OHVitD) [6] [7] [9].

Serum levels of $1,25 \mathrm{OHVitD}$ are not a reliable estimative of the body storage of vitamin D. These levels may also be mild or moderate in normal osteomalacia, as a result of secondary hyperparathyroidism associated with 
this condition [12].

\subsubsection{Vitamin D Deficiency}

The most important source of vitamin D for humans is the exposure to sunlight. However, there are relevant sun exposure restrictions, such as the increased risk of skin cancer associated with it, which leads to an increased use of sunscreen and hats [13]. A possible cause of the widespread of vitamin D deficiency is the lack of sun exposure [14]. This deficiency may also be related to the onset of cardiovascular diseases [5].

It has been suggested that 5 to 30 minutes of sun exposure, at least twice a week, is adequate for vitamin D synthesis [15] [16]. This should include exposure of the skin of arms (or legs, without sunscreen), from ten o'clock in the morning to three o'clock in the afternoon, in Brazil. Unfortunately, sun exposure indoors, as through a glass window, is not enough to produce adequate levels of vitamin D [17].

\subsubsection{Vitamin D Supplementation}

In the United States, the currently recommended intake of vitamin D is of $400 \mathrm{IU} /$ day for those patients from 51 to 70 years of age, and 600 IU/day for those aged $>70$ years [7], but these suggestions are under current review by the US Institute of Medicine, as new data come out.

The Food and Nutrition Board of the Institute of Medicine (IOM) recently updated the Dietary Reference Intake (DRI) for vitamin D [17]. The IOM recommendation is of 600 IU/day of vitamin D for subjects aged from 9 to 70 years, and $800 \mathrm{IU} /$ day for patients $>70$ years of age [16].

The Women's Health Study showed that the intake of 511 IU/day or more vitamin D was associated with a lower risk of developing type 2 diabetes, in comparison with the intake of $159 \mathrm{IU} /$ day or less $(2.7 \%$ vs. $5.6 \%$ of the cohort developed DM2) [17].

Vitamin D excess is a rare cause of hypercalcemia. I would take an ingestion of 5000 to $10,000 \mathrm{IU} /$ day, for several months, to cause hypervitaminosis $\mathrm{D}$. This condition is easily preventable by measuring levels of $25-\mathrm{OH}$ vitamin D [18].

\subsection{Type 2 Diabetes Mellitus}

The number of people with diabetes worldwide is expected to rise from 171 million in 2000 to 366 million in 2030 [19]. The International Diabetes Federation estimates that the number of people with diabetes around the world will reach almost 285 million, or $7 \%$ of the world population. This number is expected to exceed 435 million by 2030 [20] in the United States, where 79 million people have prediabetes [5].

An increased prevalence of DM2 has been described in vitamin D deficient individuals [11].

Recently, studies conducted in animals and humans argued if vitamin D might play a role in the development of DM2. To date there is no evidence of this hypothesis, but further studies are required to clarify the role of Vitamin $\mathrm{D}$ in the genesis of diabetes [21].

\section{Vitamin D and Type 2 Diabetes Mellitus}

Currently, vitamin D deficiency is considered a public health problem worldwide, because of its implications in the development of various diseases, among them DM2, obesity and hypertension [22].

Treatment with 3000 IU per day, for six months, in a group of individuals that did reached $70 \%$ of normal values of vitamin D improved insulin sensitivity in people with diabetes [11] [23]. Low vitamin D levels ( $<25$ $\mathrm{ng} / \mathrm{mL}$ ) in general, have been associated with insulin resistance and obesity [23].

Alvareze Ashraf, in their meta-analysis of two prospective cross-sectional studies, showed that vitamin D insufficiency $(20-29 \mathrm{ng} / \mathrm{mL})$ and deficiency $(<20 \mathrm{ng} / \mathrm{mL})$ has direct and indirect effects on insulin secretion and action [24].

DM2 is associated with the presence of insulin resistance and systemic inflammation, and there are some links between vitamin D pathophysiology and diabetes [21]. One hypothesis suggests that there would be an influence of the circulating 1,25OHvitD in the beta cell receptor, but no evidence has been found so far [19].

\section{Results}

This study surveyed 38 women and 16 men of $55.8 \pm 12.6$ years old, where $78.7 \%$ were white, $7.4 \%$ were Afro-Brazilians and $14.8 \%$ were mulatto. All respondents were type 2 diabetic patients, and $72.2 \%$ of the pa- 
Table 1. Clinical and laboratory tests.

\begin{tabular}{|c|c|c|c|c|c|c|c|}
\hline N Sample & Age & Presence of DM2 & LDL & HDL & BMI & Glycemia & 25-OH Vit D \\
\hline 54 & $55.8 \pm 12.6$ years & $100 \%$ & $109.1 \pm 46.1 \mathrm{mg} / \mathrm{dL}$ & $39.6 \pm 8.8 \mathrm{mg} / \mathrm{dL}$ & $30.2 \pm 4.4 \mathrm{~kg} / \mathrm{m}^{2}$ & $169.8 \pm 74.5 \mathrm{mg} / \mathrm{dL}$ & $23.4 \pm 8.3 \mathrm{ng} / \mathrm{mL}$ \\
\hline
\end{tabular}

tients had hypertension.

A total of $72.2 \%$ of those surveyed had dyslipidemia, based on the reference values described in the current Dyslipidemia Guidelines [25], with mean values of LDL $109.1 \pm 46.1 \mathrm{mg} / \mathrm{dL}$, and $39.6 \pm 8.8 \mathrm{mg} / \mathrm{dL}$ for HDL.

BMI means was of $30.2 \pm 4.4 \mathrm{~kg} / \mathrm{m}^{2}$, and fasting glucose concentrations were of $169.8 \pm 74.5 \mathrm{mg} / \mathrm{dL}$, and therefore they are be classified according to (WHO, 1995) [26], as class 1 obese patients. In addition, 13\% of the patients had $25 \mathrm{OH}$ vitamin D levels above $30 \mathrm{mg} / \mathrm{dL}$, 50\% less than 30\% and 37\% less than $20 \mathrm{mg} / \mathrm{dL}$ values under $10 \mathrm{mg} / \mathrm{dL}$ were not found, based on the reference values described by the São Camilo Lab Group [18] (Table 1).

\section{Discussion and Conclusion}

Vitamin D deficiency is defined as $250 \mathrm{H}$ vitamin D levels under $30 \mathrm{ng} / \mathrm{mL}$. It is treated with oral supplementation, and with exposure to sunlight on a daily basis, for 15 to 30 minutes. Regular laboratory tests are needed to control this deficiency. Absorption of vitamin D occurs through the skin, by B ultraviolet rays and by the intake of foods rich in vitamin D.

The use of hats and sunscreen may reduce the synthesis of vitamin D. Cold countries with lower sun brightness, which is the case in countries far from the tropics, have a higher prevalence of vitamin $\mathrm{D}$ deficiency.

Low levels of vitamin D are associated with type 2 diabetes. The results of this study showed a vitamin D deficiency in all the 54 diabetic patients studied in Mangueirinha-Paraná, Southern Brazil. These patients had also dyslipidemia and class 1 obesity, which may affect the outcomes reported.

Diabetic patients are at higher risk of developing vitamin D deficiency. This condition should be considered in all type 2 diabetic patients, in order to control vitamin D levels and possibly prevent diseases associated with low levels of this vitamin.

\section{Acknowledgements}

The authors would like to thank IPEMED Brazil for supporting continuous research towards a better medical education in Brazil and abroad.

\section{References}

[1] Sociedade Brasieira de Diabetes (2015) Tratamento e acompanhamento do Diabetes Mellitus. Diretrizes da Sociedade Brasileira de Diabetes. Diagraphic Editora.

[2] Kulie, T., Groff, A., Redmer, J., Hounshell, J. and Shrager, S. (2009) Vitamina D: Uma revisão baseada em evidencias. Journal of the American Board of Family Medicine, 22, 698-706. http://dx.doi.org/10.3122/jabfm.2009.06.090037

[3] Escobar, F.A. (2009) Relação entre Obesidade e Diabetes Mellitus Tipo II em Adultos. Caderno UniFoa, 11, 69-72.

[4] Pienta, W.P. (2010) Diabetes Mellitus. Disciplina de Endocrinologia e Metabologia do Departamento de Clínica Médica. Faculdade de Medicina de Botucatu-UNESP.

[5] Santos, A. (2011) Papel da Vitamina D no risco cardiovascular. Revista Factores de Risco, 23, 18-23.

[6] Premaor, M.O. and Furlanetto, T.W. (2006) Hipovitaminose D em adultos: Entendendo melhor a apresentação de uma velha doença. Arquivos Brasileiros de Endocrinologia \& Metabologia, 50, 25-37. http://dx.doi.org/10.1590/S0004-27302006000100005

[7] Munns, C., Zacharin, M.R., Rodda, C.P., Batch, J.A., Morley, R., Cranswick, N.E., et al. (2006) Prevention and Treatment of Infant and Childhood Vitamin D Deficiency in Australia and New Zealand: A Consensus Statement. Medical Journal of Australia, 185, 268-272.

[8] Holick, M.F. (2007) Vitamin D Deficiency. New England Journal of Medicine, 357, 266-281. http://dx.doi.org/10.1056/NEJMra070553

[9] Bandeira, F., Griz, L., Dreyer, P., Eufrazino, C., Bandeira, C. and Freese, E. (2006) Vitamin D Deficiency: A Global Perspectiv. Arquivos Brasileiros de Endocrinologia \& Metabologia, 50, 640-646. http://dx.doi.org/10.1590/S0004-27302006000400009 
[10] Junior, E.P.S., Fernandes, D.C., Almeida, A.T.F., Borges, F.A. and Novaes, J.A.R. (2011) Epidemiologia da Deficiência de Vitamina D. Revista Científica do ITPAC, 4, 1-5.

[11] Borissova, A.M., Tankova, T., Kirilov, G., Dakovska, L. and Kovacheva, R. (2003) The Effect of Vitamin D3 on Insulin Secretion and Peripheral Insulin Sensitivity in Type 2 Diabetic Patients. International Journal of Clinical Practice, 57, 258-261.

[12] Mosekilde, L. (2005) Vitamin D and the Elderly. Clinical Endocrinology, 62, 265-281. http://dx.doi.org/10.1111/j.1365-2265.2005.02226.x

[13] Marques, C.D.L., Dantas, A.T., Fragoso, T.S. and Duarte, A.L.B.P. (2010) A importância dos níveis de Vitamina D nas doenças Autoimunes. Revista Brasileira de Reumatologia, 50, 67-80. http://dx.doi.org/10.1590/S0482-50042010000100007

[14] Holick, M.F. (2005) Vitamin D for Health and in Chronic Kidney Disease. Seminars in Dialysis, 18, $266-275$. http://dx.doi.org/10.1111/j.1525-139X.2005.18402.x

[15] Liu, S., Song, Y., Ford, E.S., Manson, J.E., Buring, J.E. and Ridker, P.M. (2005) Dietary Calcium, Vitamin D, and the Prevalence of Metabolic Syndrome in Middle-Aged and Older U.S. Women. Diabetes Care, 28, 2926-2932. http://dx.doi.org/10.2337/diacare.28.12.2926

[16] Binkley, N. (2007) Low Vitamin D Status despite Abundant Sun Exposure. The Journal of Clinical Endocrinology \& Metabolism, 92, 21-30. http://dx.doi.org/10.1210/jc.2006-2250

[17] Institute of Medicine Food and Nutrition Board (2010) Dietary Reference Intakes for Calcium, Phosphorous, Magnesium, Vitamin D, and Fluoride. National Academy Press, Washington DC.

[18] Grupo São Camilo (2011) 25-OH Vitamina D Total. As principais Indicações de sua Dosagem. http://www.gruposaocamilo.com.br/media/arquivos/apoio/0705171709.pdf

[19] Anastassios, G. and Pittas, M.D. (2010) Vitamin D and Diabetes. The Journal of Steroid Biochemistry and Molecular Biology, 121, 425-429. http://dx.doi.org/10.1016/j.jsbmb.2010.03.042

[20] International Diabetes Federation (2009) IDF Diabetes Atlas. 4th Edition, International Diabetes Federation, Brussels.

[21] Hu, F.B., Manson, J.E., Stampfer, M.J., Colditz, G., Liu, S., Solomon, C.G. and Willett, W.C. (2001) Diet, Lifestyle, and the Risk of Type 2 Diabetes Mellitus in Women. The New England Journal of Medicine, 345, 790-797. http://dx.doi.org/10.1056/NEJMoa010492

[22] Schuch, N.J., Garcia, V.C. and Martin, L.A. (2009) Vitamina D e doenças endocrinometabólicas. Arquivos Brasileiros de Endocrinologia \& Metabologia, 53, 625-633. http://dx.doi.org/10.1590/S0004-27302009000500015

[23] Hahn, S., Haselhorst, U., Tan, S., Quadbeck, B., Schmidt, M., Roesler, S., et al. (2006) Low Serum 25-Hydroxyvitamin D Concentrations Are Associated with Insulin Resistance and Obesity in Women with Polycystic Ovary Syndrome. Experimental and Clinical Endocrinology \& Diabetes, 114, 577-583. http://dx.doi.org/10.1055/s-2006-948308

[24] Alvarez, J.A. and Ashraf, A. (2010) Role of Vitamin D in Insulin Secretion and Insulin Sensitivity for Glucose Homeostasis. International Journal of Endocrinology, 2010, Article ID: 351385. http://dx.doi.org/10.1155/2010/351385

[25] Stone, J.R., Robinson, J.G., Lichtenstein, A.H., Merz, C.N.B., Blum, C.B., Eckel, R.H., et al. (2013) 2013 ACC/AHA Guideline on the Treatment of Blood Cholesterol to Reduce Atherosclerotic Cardiovascular Risk in Adults: A Report of the American College of Cardiology/American Heart Association Task Force on Practice Guidelines. Journal of the American College of Cardiology, 63, 2889-2934. http://dx.doi.org/10.1016/j.jacc.2013.11.002

[26] Fernandes Filho, J. (2003) A prática da Avaliação Física. Testes, medidas e avaliação física em escolares, atletas e academias de ginástica. 2nd Edition, Shape, Rio de Janeiro. 